Article

\title{
Experiment on Pressure Pulsation of Axial Flow Pump System with Different Runaway Head
}

\author{
Jing Dai ${ }^{1}$, Xueqin Liu ${ }^{2}$, Congbing Huang ${ }^{3}$, Xuemei $\mathrm{Xu}^{2}{ }^{2}$, Ge Bu ${ }^{2}$, Ziye Zhong ${ }^{4}$, Feng $\mathrm{Xu}^{4}$ and Qifan Dai ${ }^{4, *}$ \\ 1 College of Water Conservancy and Hydropower Engineering, Hohai University, Nanjing 210098, China; \\ dailaoban1992@sina.com \\ 2 Jiangsu Water Conservancy Survey and Design Institute Co., Ltd., Yangzhou 225000, China; \\ liuxueqin1990@sina.com (X.L.); xuxuemei1909@sina.com (X.X.); buge2020@sina.com (G.B.) \\ 3 Jiangsu Aerospace Hydraulic Equipment Co., Ltd., Yangzhou 225000, China; congbinghuang@sina.com \\ 4 Jiangsu Province General Irrigation Canal Management, Huai'an 223200, China; \\ zhongziye2021@sina.com (Z.Z.); xufeng19766@sina.com (F.X.) \\ * Correspondence: daiqifan@163.com; Tel.: +86-182-6062-6517
}

Citation: Dai, J.; Liu, X.; Huang, C.; Xu, X.; Bu, G.; Zhong, Z.; Xu, F.; Dai, Q. Experiment on Pressure Pulsation of Axial Flow Pump System with Different Runaway Head. Processes 2021, 9, 1597. https:// doi.org/10.3390/pr9091597

Academic Editor: Hussein A. Mohammed

Received: 4 July 2021

Accepted: 4 September 2021

Published: 6 September 2021

Publisher's Note: MDPI stays neutral with regard to jurisdictional claims in published maps and institutional affiliations.

Copyright: (c) 2021 by the authors. Licensee MDPI, Basel, Switzerland. This article is an open access article distributed under the terms and conditions of the Creative Commons Attribution (CC BY) license (https:// creativecommons.org/licenses/by/ $4.0 /)$.

\begin{abstract}
The runaway condition is a damage condition for pumps and turbines which can induce the wake vortex, reverse flow, and severe pressure pulsation. This study aimed to research the characteristics of pressure pulsation of axial flow pumps under different runaway conditions, and the runaway model test was performed with different blade angles and heads. Moreover, four pressure sensors were uniformly arranged at the impeller inlet section to eliminate the random error. The time domain and frequency domain analysis were the main methods to obtain the change regulations. Results showed that the pressure pulsation under the runaway condition are mainly influenced by the rotation frequency, blade passing frequency, and wake vortex frequency. The dimensionless pressure pulsation coefficient of rotation frequency and wake vortex frequency increased obviously with the runaway head increasing, but changed little with different blade angles. In addition, the dimensionless pressure coefficient of wake vortex frequency of the sensors around the impeller inlet section differed a lot, which means that the wake vortex core is not in center of the rotation axis. The average dimensionless pressure pulsation coefficient of wake vortex frequency is higher than that of rotation frequency with the same runaway head, owing to the severer wake vortex.
\end{abstract}

Keywords: model test; axial flow pump; runaway process; pressure pulsation; wake vortex frequency

\section{Introduction}

The runaway condition of pumps is an extreme turbine condition in which the flow and rotation direction are the same with those of turbine condition. When a pump or turbine suddenly loses power by incident, the water in the pipe system will flow back and the impeller will rotate in the opposite direction [1,2]. Under the influence of the water level difference between the upstream and the downstream, the rotation speed of the impeller continues to speed up until the maximum value, called runaway speed. Under the runaway condition, the centrifugal force in the impeller and the vortex rope in the inlet pipe are produced inevitably [3], which will cause harm to the rotation device and constraint components [4]. In addition, the unstable flow pattern will generate severe pressure pulsation, which may damage the pump device [5]. Therefore, studying the runaway condition is of great importance for the safety of pumps or turbines.

Model test and numerical simulation are the main methods to study hydraulic machinery during transient processes. For credibility and authenticity, some scholars studied the runaway condition through the model test. Fortin et al. [6,7] measured the pressure on the impeller blade surface during the runaway process to relate the pressure and the vortex rope. Trivedi et al. [8,9] compared the pressure pulsation frequency with different blade angles during the runaway process. The high amplitude of the pressure pulsation 
may decrease the service life of the impeller blade. Zhang et al. [10] found that pressure pulsations were mainly influenced by the guide vane opening under the turbine mode. With the development of computer technology, the computational fluid dynamics (CFD) is widely used in fluid machinery simulation. Trivedi et al. [11] adopted the scale-adaptive simulation (SAS) shear stress transport (SST) model to study the runaway condition. The simulation results were verified with the model test. Hosseinimanesh et al. [12] simulated the runaway process with different Wicket gate openings. Zhang et al. [13] researched the S-shaped characteristics of pump-turbines with different rotational inertia, which showed that a large rotational inertia is easier than a small one to induce abrupt increases in runner radial forces. Yang et al. [14] compared the flow pattern and pressure pulsation of the pump with different specific speeds, indicating that the lower specific speed turbines more easily enter the reverse pump mode. Zhang et al. $[15,16]$ considered the influence of water compressibility on the transient process to combine the one-dimensional (1D) water conveyance system and three-dimensional (3D) pump-turbine.

When it comes to the selection of the turbulence model and grid number during the simulation, different simulation situations and research goals result in different choices. For guiding the project in reality, the researchers prefer the standard $k-\varepsilon$, Realized $k-\varepsilon$, and RNG $k-\varepsilon$ turbulence models with a lower grid number and more robust simulation $[12,17,18]$. For studying the intricate flow pattern in the pipe, the scholars tend to adopt the SST $k-\omega$ and SAS-SST turbulence models, which can simulate the flow near the wall accurately $[11,19]$. As for hydraulic machinery with long-distance water pipelines, the one-dimensional method of characteristics (MOC) is an appropriate method for runaway simulation; of course, there is no need for the turbulence model and grid generation [20,21].

The external characteristics of different pump types in the runaway situation differ significantly. As for the centrifugal pump with high head, the runaway oscillation process is often accompanied by an $\mathrm{S}$ region, which means the rotation speed and flow rate cannot converge to a stable value $[16,22,23]$. When comes to the axial flow pump with low head, the impeller torque will converge to zero during the runaway process, and the stable rotation speed contributes to the vortex rope [6,7]. Since the runaway condition is a complex state, which involves unsteady rotation speed, reverse discharge, vortices evolution, and complex flow patterns, and scholars study the unstable state from different aspects. The pressure fluctuation amplitude under runaway process is widely researched, because the rotation speed is mainly influenced by the torque, and torque accounts from the integral of blade-surface pressure around the axis $[24,25]$. Besides, the vortex in the pipe is also the focus, which results in the entropy generation $[22,26,27]$.

The objective of this paper was to investigate the influence of runaway head on the pressure pulsation. Although the research of pressure fluctuation is common during the runaway simulation, there are still few studies using the method of model test. The remainder of this paper is organized as follows. A brief experimental setup of the model test rig and monitoring points are introduced in Section 2. Section 3 mainly contains the time domain and frequency domain analysis of the pressure pulsation. Finally, Section 4 summarizes this work and details the potential research issues.

\section{Experiment Setup}

In this research, the pressure fluctuation of an axial flow pump was studied under different runaway conditions. The main characteristic parameters of the prototype pump and model pump are displayed in Table 1. The model pump tests were carried out on the closed hydraulic machinery test rig at the Jiangsu Aerospace Hydraulic Equipment Co., Ltd., Yangzhou, China. Additionally, the test rig meets the requirement of International Standard Organization (ISO) 9906. Figure 1 presents the model test rig for the axial flow pump with low head, including low pressure tank, inlet conduit, impeller, guide vanes, outlet conduit, high-pressure tank, and electric motor. During the runaway condition, the flow pattern fluctuates violently in the inlet conduit due to the backflow and the impeller rotating in the opposite direction. In order to research the characteristics of pressure fluctu- 
ation in the inlet conduit, the data acquisition system with 10 channels produced by the HELM company was selected for pressure-signal sampling. In addition, the monitoring points (MP) of the pressure transducers (EM96369M series) are shown in Figure 2, i.e., the MP1-4 were uniformly arranged at the interface of the impeller and the inlet conduit; MP5 and MP6 were fixed at the directly above and below the inlet conduit, respectively. The main specifications of the model test rig and the pressure sensor applied for pressure pulsation are presented in Table 2. All model tests were conducted in conformity with the International Electrotechnical Commission (IEC) Standard 60193.

Table 1. Characteristic parameters of the axial flow pump system.

\begin{tabular}{cccc}
\hline \multirow{2}{*}{ Parameter } & Symbol & \multicolumn{2}{c}{ Value } \\
\cline { 3 - 4 } & & Prototype Pump & Model Pump \\
\hline Diameter of impeller & $D[\mathrm{~m}]$ & 3.1 & 0.3 \\
Number of impeller blades & $Z_{\mathrm{i}}[-]$ & 5 & 5 \\
Number of guide vanes & $Z_{\mathrm{g}}[-]$ & 7 & 7 \\
Blade angle & $\alpha\left[{ }^{\circ}\right]$ & $-6 \sim 6$ & $-6 \sim 6$ \\
Maximum head & $H_{\max }[\mathrm{m}]$ & 4.78 & 4.78 \\
Design head & $H_{\mathrm{d}}[\mathrm{m}]$ & 4.28 & 4.28 \\
Planning average head & $H_{\mathrm{pl}}[\mathrm{m}]$ & 3.06 & 3.06 \\
Perennial average head & $H_{\text {pe }}[\mathrm{m}]$ & 2.05 & 2.05 \\
Minimum head & $H_{\min }[\mathrm{m}]$ & 1.28 & 1.28 \\
Design rotation speed & $n[\mathrm{r} / \mathrm{min}]$ & 125 & 1291.7 \\
Design discharge & $Q\left[\mathrm{~m}^{3} / \mathrm{s}\right]$ & 30 & 0.281 \\
\hline
\end{tabular}

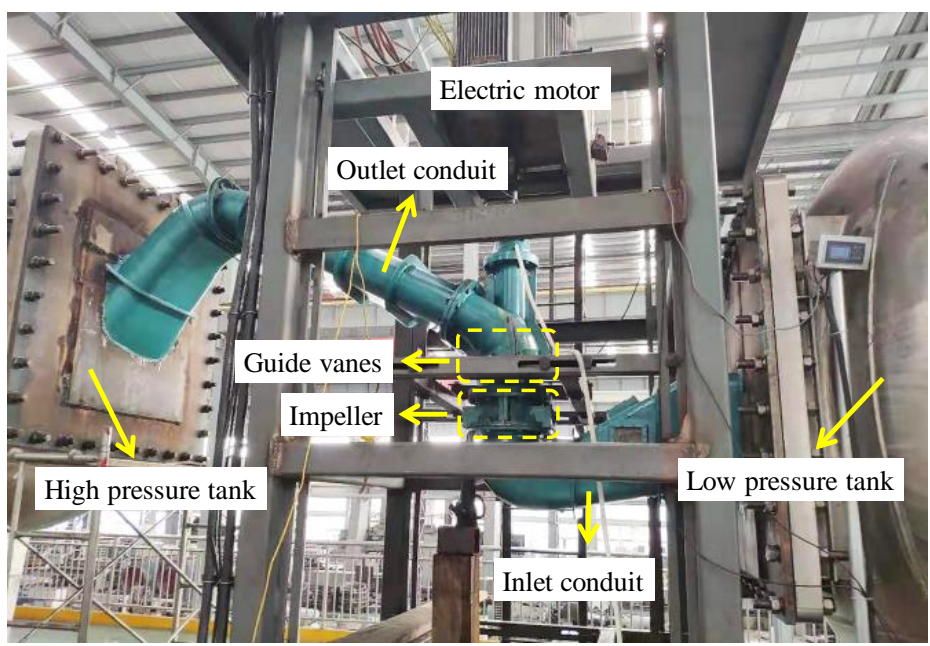

Figure 1. Model test rig for the axial flow pump with a low head.
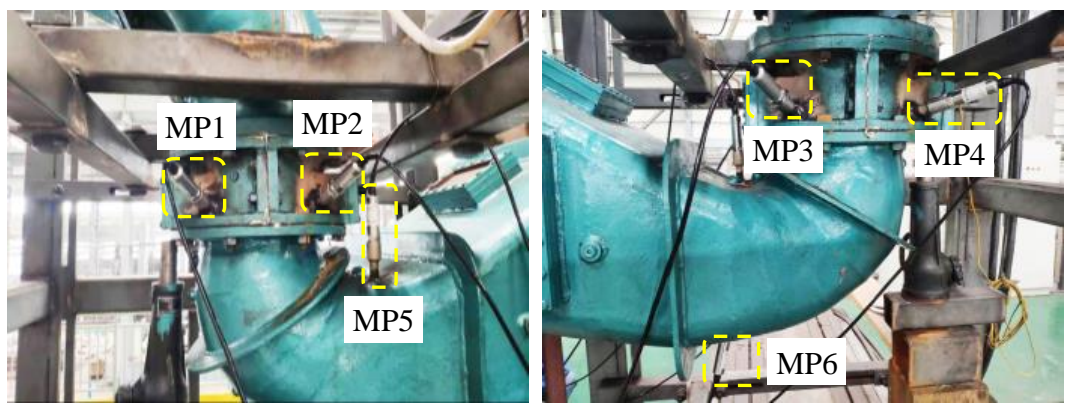

Figure 2. Monitoring points of pressure pulsation. 
Table 2. Characteristic parameters of the test rig and pressure sensor.

\begin{tabular}{ccc}
\hline Item & Parameter & Value \\
\hline & Maximum pump head $[\mathrm{m}]$ & 160 \\
& Maximum discharge $\left[\mathrm{m}^{3} / \mathrm{s}\right]$ & 0.778 \\
The test rig & Maximum torque $[\mathrm{N} \cdot \mathrm{m}]$ & 3000 \\
& Generating power $[\mathrm{kW}]$ & 250 \\
& Local gravity acceleration $\left[\mathrm{m}^{2} / \mathrm{s}\right]$ & 9.795 \\
& Test accuracy in efficiency $[\%]$ & \pm 0.3 \\
\hline & Measurement range $[\mathrm{kPa}]$ & $0-150$ \\
Pressure sensor & Sensitivity $[\mathrm{mv} / \mathrm{kPa}]$ & 33.3 \\
& Response time range $[\mathrm{ms}]$ & $0-2$ \\
& Sampling frequency $[\mathrm{kHz}]$ & 100 \\
& Constant current excitation $[\mathrm{mA}]$ & $4-20$ \\
& Uncertainty $[\%]$ & \pm 0.02 \\
\hline
\end{tabular}

\section{Results and Discussions}

\subsection{Runaway Curves and Working Conditions}

The runaway rotation speed curves at different blade angles are displayed in Figure 3. On the one hand, the rotation speed increased significantly with the runaway head, because the high runaway head brings about a large discharge, increasing the rotation speed. On the other hand, the rotation speed decreased slightly with the blade angles, which indicates the influence of the blade angle on the flow pattern. In order to compare the characteristics of pressure fluctuation under different runaway conditions, four different water heads and four different blade angles were adopted when sampling the pressure signal during the runaway process. Namely, the test runaway head contains $0.65 \mathrm{~m}, 1.28 \mathrm{~m}, 2.05 \mathrm{~mm}$ and $3.06 \mathrm{~m}$; meanwhile, the test blade angle includes $-4^{\circ},-2^{\circ}, 0^{\circ}$, and $+2^{\circ}$. The characteristic parameters at $\alpha=+2^{\circ}$ with different runaway head are shown in Table 3 , and the equations of rotation frequency, blade passing frequency (BPF), and impeller rotation cycle time are as follows:

$$
f_{n}=\frac{n}{60} ; \quad f_{B P F}=Z_{\mathrm{i}} f_{n} ; \quad T=\frac{1}{f_{n}}
$$

where $n$ is the rotational speed $[\mathrm{r} / \mathrm{min}], Z_{\mathrm{i}}$ is the number of the impeller blade, $f_{n}$ is the rotational frequency $[\mathrm{Hz}], f_{\mathrm{BPF}}$ is the blade pass frequency $[\mathrm{Hz}]$, and $T$ is the impeller rotation cycle time $[\mathrm{s}]$.

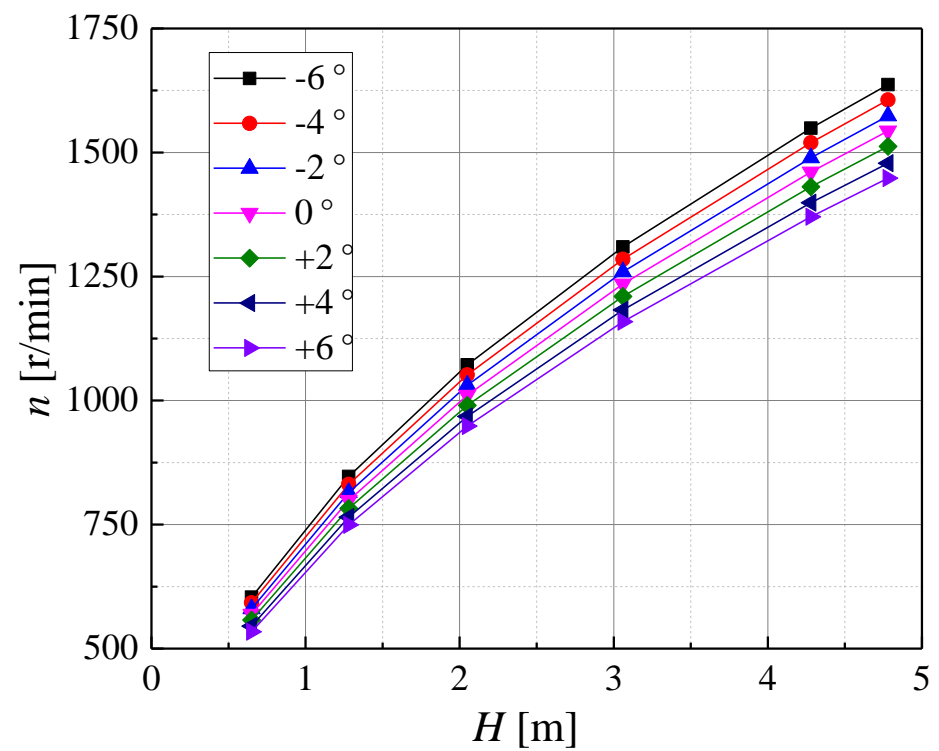

Figure 3. The runaway speed of the axial flow pump under different water heads. 
Table 3. Characteristic parameters at $\alpha=+2^{\circ}$ with different runaway heads.

\begin{tabular}{ccccc}
\hline Runaway Head, $\boldsymbol{H}[\mathbf{m}]$ & $\begin{array}{c}\text { Rotation Speed, } \boldsymbol{n} \\
{[\mathbf{r} / \mathbf{m i n}]}\end{array}$ & $\begin{array}{c}\text { Rotation Frequency, } \boldsymbol{f}_{\boldsymbol{n}} \\
{[\mathbf{H z}]}\end{array}$ & $\begin{array}{c}\text { Blade Passing } \\
\text { Frequency, } \boldsymbol{f}_{\mathbf{B P F}}[\mathbf{H z}]\end{array}$ & $\begin{array}{c}\text { Impeller Rotation } \\
\mathbf{C y c l e}, \boldsymbol{T}[\mathbf{s}]\end{array}$ \\
\hline 0.65 & 557.6 & 9.29 & 46.45 & 0.1076 \\
1.28 & 782.5 & 13.04 & 65.20 & 0.0767 \\
2.05 & 990.3 & 16.51 & 82.55 & 0.0606 \\
3.06 & 1209.9 & 20.17 & 100.85 & 0.0496 \\
\hline
\end{tabular}

\subsection{Unsteady Pressure Pulsation Analysis}

In order to eliminate the influence of the runaway head on the amplitude of pressure pulsation, the dimensionless pressure coefficient $C_{p}$ [28-30] is introduced as follows:

$$
C_{p}=\frac{p-\bar{p}}{0.5 \rho u_{2}^{2}}
$$

where $\rho$ is the water density $\left[\mathrm{kg} / \mathrm{m}^{3}\right], p$ is the transient pressure $[\mathrm{Pa}], \bar{p}$ is the average pressure [Pa], and $u_{2}$ is the tangential velocity on impeller blade tip at $\alpha=+2^{\circ}$ with $H=3.06 \mathrm{~m}[\mathrm{~m} / \mathrm{s}]$.

Since the rotation cycle time varies with the rotation speed, the number of impeller rotation cycles was designed as follows:

$$
N=\frac{t}{T}
$$

where $t$ is the signal time [s].

The time domain pulsation coefficient curves of at $\alpha=+2^{\circ}$ with different runaway head are presented in Figure 4. Figure 4a shows the pulsation coefficient curves at $H=0.65 \mathrm{~m}$. Figure $4 \mathrm{~b}$ shows the pulsation coefficient curves at $H=1.28 \mathrm{~m}$. Figure $4 \mathrm{c}$ shows the pulsation coefficient curves at $H=2.05 \mathrm{~m}$. Figure $4 \mathrm{~d}$ shows the pulsation coefficient curves at $H=3.06 \mathrm{~m}$. The characteristics of time domain pressure pulsation among MP1-4 are similar, owing to the position of uniform distribution at the interface of the impeller and the inlet conduit. In Figure $4 \mathrm{a}$, it is shown that the pressure signals among MP1-4 contain about 30 peaks and valleys in six impeller rotation cycles, i.e., five signal pulses per impeller rotation cycle. In addition, there exist six obvious signal pulses in six impeller rotation cycles among MP1-4 with $H=3.06 \mathrm{~m}$ (Figure $4 \mathrm{~d}$ ). As for the pressure signals among MP1-4 with $H=1.28 \mathrm{~m}$ and $H=2.05 \mathrm{~m}$ (Figure $4 \mathrm{~b}, \mathrm{c}$ ), the concrete number of signal pulses in six impeller rotation cycle are not easily identified, because the large peaks and valleys are nested with the small ones. However, the signal pulses per impeller rotation cycle among MP1-4 were the same as each other under the same conditions, and the tendency of the pressure to change was similar. Since the limitation of structural design of the model pump, the pressure sensors cannot evenly arrange five at the impeller inlet, which inevitably leads to the phase difference of time domain pulsation coefficient among MP1-4.

As for the time domain pulsation characteristics of MP5 and MP6, the number of signal pulses in six impeller rotation cycles and the trends in pressure changes were different from those among MP1-4. Obviously, the main factors affecting the characteristics of pressure fluctuation were different. 


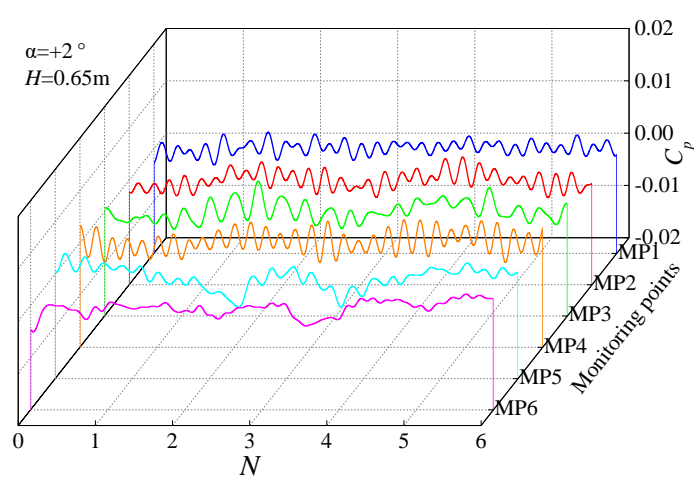

(a)

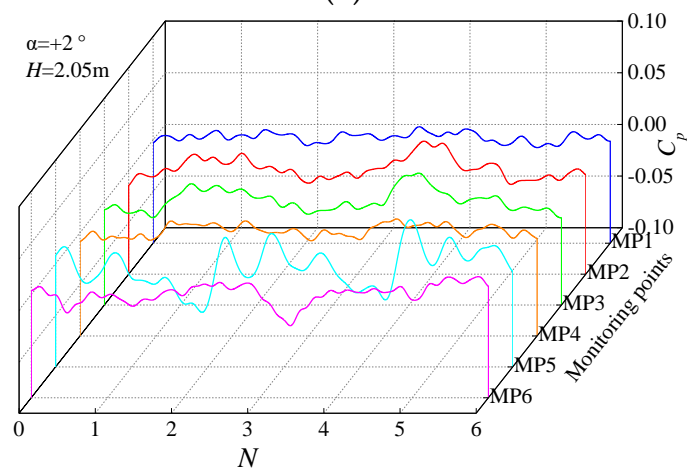

(c)

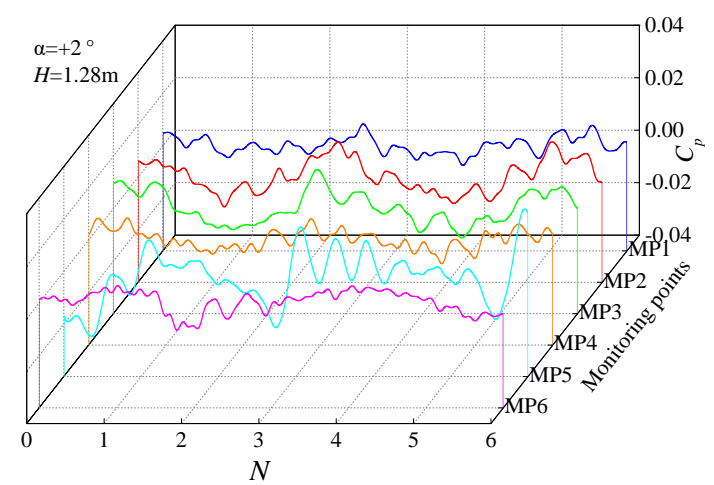

(b)

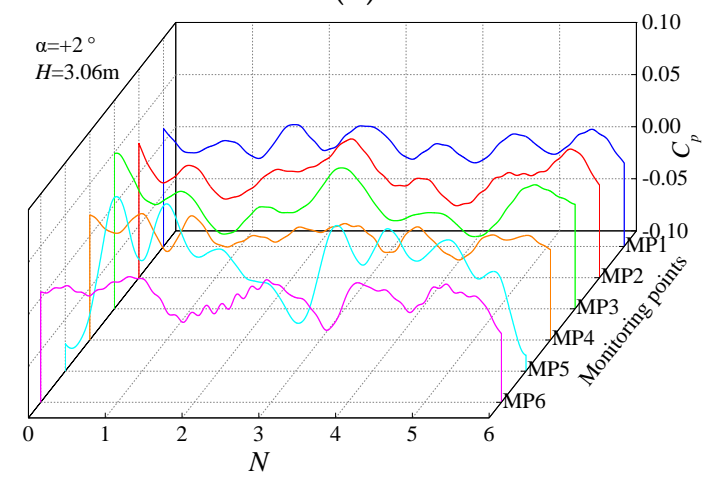

(d)

Figure 4. Comparison of time domain pressure pulsation coefficient of different MPs at $\alpha=+2^{\circ}$ with different runaway heads. (a) shows the pulsation coefficient curves at $H=0.65 \mathrm{~m}$. (b) shows the pul-sation coefficient curves at $H=1.28 \mathrm{~m}$. (c) shows the pulsation coefficient curves at $H=2.05 \mathrm{~m}$. (d) shows the pulsation coefficient curves at $H=3.06 \mathrm{~m}$.

The pulsation coefficient curves of the frequency domain at $\alpha=+2^{\circ}$ with different runaway heads are presented in Figure 5. Figure 5a shows the pulsation coefficient curves at $H=0.65 \mathrm{~m}$. Figure $5 \mathrm{~b}$ shows the pulsation coefficient curves at $H=1.28 \mathrm{~m}$. Figure $5 \mathrm{c}$ shows the pulsation coefficient curves at $H=2.05 \mathrm{~m}$. Figure $5 \mathrm{~d}$ shows the pulsation coefficient curves at $H=3.06 \mathrm{~m}$. The rotation frequency times $\left(f / f_{n}\right)$ are introduced in order to uniform rotation frequency. Without considering the low frequency, i.e., $f$ is less than $f_{n}$, the characteristics of frequency domain pressure pulsation among MP1-4 were under the influence of rotation frequency. In Figure $5 a$, it is represented that the main frequency of pressure pulsation among MP1-4 was $5 f_{n}=45.46 \mathrm{~Hz}$, i.e., the blade passing frequency $f_{\mathrm{BPF}}$, and the sub-frequency was $f_{n}, 2 f_{n}$ and $3 f_{n}$. Additionally, the main frequency $f_{\mathrm{BPF}}$ among MP1-4 explains that there are five obvious signal pulses in an impeller rotation cycle (Figure 4a). As for the pressure spectra among MP1-4 with $H=1.28 \mathrm{~m}$ (Figure 5b), the $2 f_{n}$ is the domain among high-frequency harmonics of $f_{n}$, whereas $f_{n}$ and $f_{\mathrm{BPF}}$ are the secondary. With the situation of $H=3.06 \mathrm{~m}$ (Figure $5 \mathrm{~d}$ ), the main frequency was $f_{n}$, and the sub-frequency was $2 f_{n}$ and $f_{\text {BPF. }}$. Moreover, the main frequency $f_{n}$ among MP1-4 makes it clear that there exists one obvious signal pulses per impeller rotation cycle (Figure $4 \mathrm{~d}$ ). In a word, without considering the super low frequency (i.e., $f / f_{n}$ is less than 1 ), the main frequency of pressure pulsation among MP1-4 transforms from $f_{\text {BPF }}$ to $f_{n}$ with the increase of the runaway head, which explains evolution of the number of signal pulses in per impeller rotation cycle. As for the pressure spectra characteristics of MP5 and MP6 (Figure 5), the main frequency is never $f_{n}$ or the high-frequency harmonics of $f_{n}$ under different conditions, which leads to the different signal pulses and pressure phase from those among MP1-4 (Figure 4). 


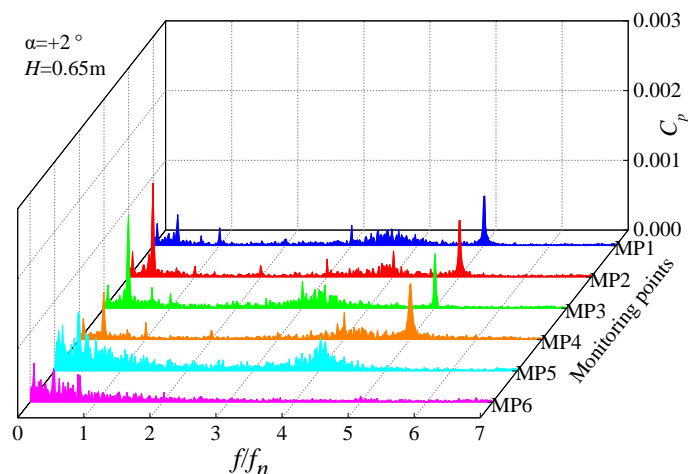

(a)

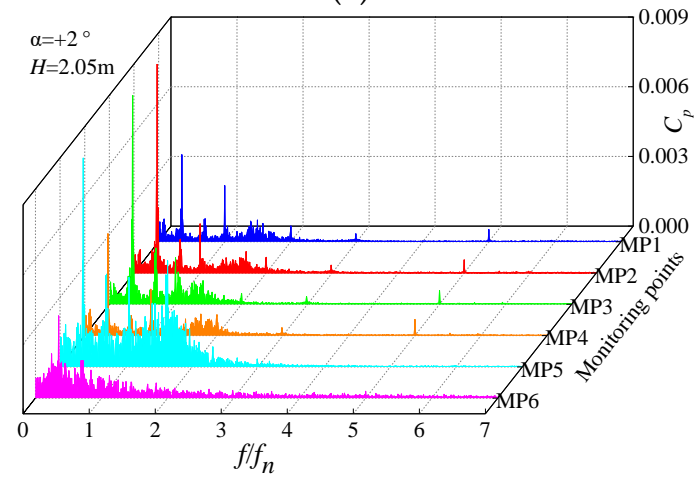

(c)

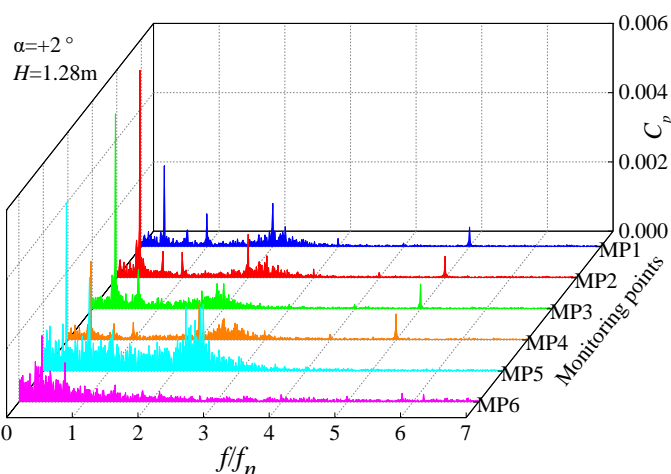

(b)

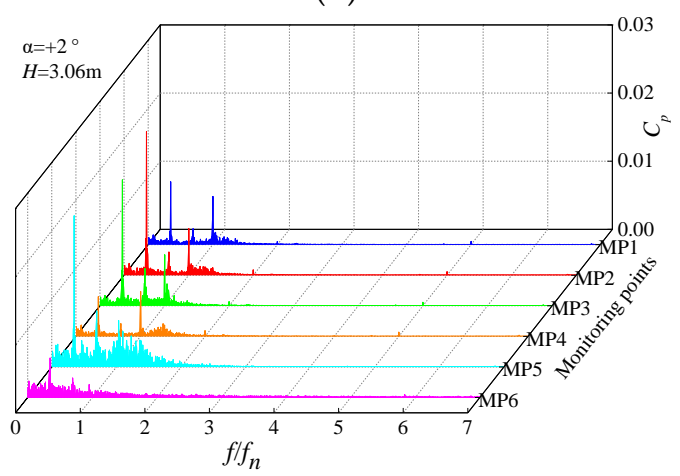

(d)

Figure 5. Comparison of frequency domain pressure pulsation coefficients of different $\mathrm{MP}$ at $\alpha=+2^{\circ}$ with different runaway heads. (a) shows the pulsation coefficient curves at $H=0.65 \mathrm{~m}$. (b) shows the pulsation coefficient curves at $H=1.28 \mathrm{~m}$. (c) shows the pulsation coefficient curves at $H=2.05 \mathrm{~m}$. (d) shows the pulsation coefficient curves at $H=3.06 \mathrm{~m}$.

The $C_{p}$ values of $f_{n}$ and $f_{\mathrm{BPF}}$ among MP1- 6 at $\alpha=+2^{\circ}$ with different runaway heads are displayed in Figure 6. It can be observed from Figure 6a that the $C_{p}$ value of $f_{n}$ increased obviously with the runaway head, which indicates that the influence of the rotation speed is enhanced with the large runaway head. Additionally, the $C_{p}$ value among MP1-4 is similar to each other, owing to the ring column arrangement. In addition, the $C_{p}$ value of MP5 is slightly lower than that of MP4 with the same runaway head. However, the $C_{p}$ value of MP6 is close to zero for the location away from the rotation axial.

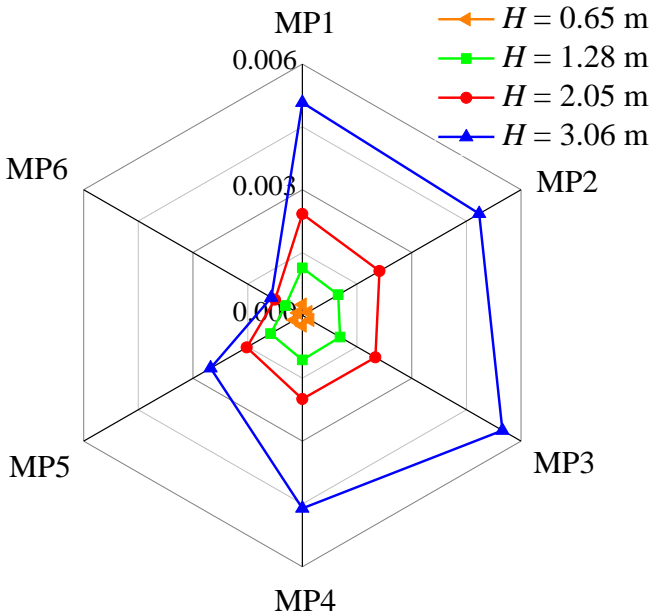

(a) $f_{n}$

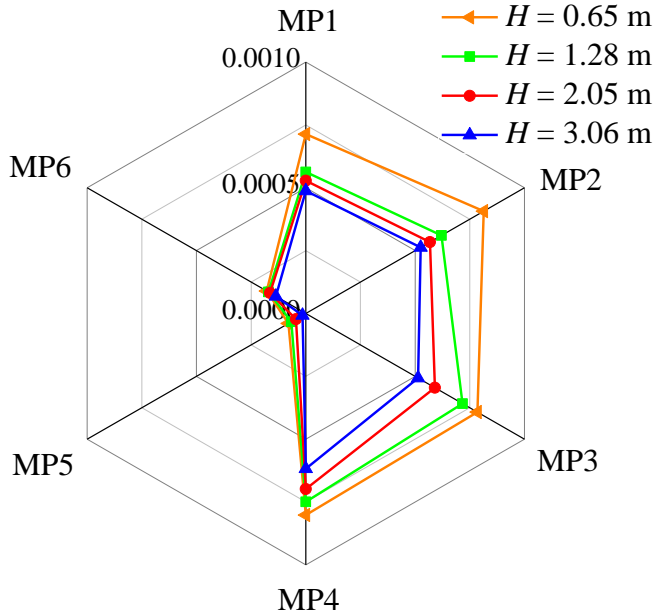

(b) $f_{\mathrm{BPF}}$

Figure 6. The $C_{p}$ vlaue of $f_{n}$ and $f_{\mathrm{BPF}}$ among MP1-6 at $\alpha=+2^{\circ}$ with different runaway heads. 
Considering the $C_{p}$ value of $f_{\mathrm{BPF}}$ in Figure $6 \mathrm{~b}$, the low change of the $C_{p}$ value is contrary to that of $f_{n}$. The $C_{p}$ value of $f_{\mathrm{BPF}}$ decreased slightly with the runaway head, which means the effect of the rotor-stator interaction (RSI) [31,32] was weakened. Besides, the $C_{p}$ value of MP5 and MP6 was close to zero, which indicates that the RSI was weakened with distance between MP and the impeller. Under normal pump and turbine conditions, the severe RSI always contributes to the high-frequency harmonics of $f_{\mathrm{BPF}}$, namely $2 f_{\mathrm{BPF}}$ and $3 f_{\mathrm{BPF}}$. However, the values of $2 f_{\mathrm{BPF}}$ and $3 f_{\mathrm{BPF}}$ were close to zero among MP1-6 under the runaway condition. This means the RSI is obviously weakened during the runaway process, and thus such amplitude of the high-frequency harmonics of $f_{\mathrm{BPF}}$ can be ignored.

According to Ref. [33], the low-frequency component of the pressure pulsation accounts from the wake vortex, and the empirical formula is as follows:

$$
f_{1}=\frac{f_{n}}{K}
$$

where $f_{1}$ is the wake vortex frequency $[\mathrm{Hz}], K$ is the empirical parameter, and the value generally ranges from three to four, but $K$ is about 2.9 under the runaway condition of our model.

When the frequency $f$ being less than $f_{n}$ is considered in Figure 5, the wake vortex rope is the main factor leading to the low frequency. In Figure $5 d$, the wake vortex frequency $f_{1}$ among MP1-6 is the same value, i.e., $7.03 \mathrm{~Hz}$, and the value $K$ under this condition is equal to 2.88. As for the other runaway head (Figure $5 \mathrm{a}-\mathrm{c}$ ), the value $K$ was equal to 2.84, 2.85 , and 2.86 . Although the value $K$ seemingly increased slightly with the runaway head, the judgement is also under the restriction of the measurement accuracy.

The $C_{p}$ value of $f_{1}$ among MP1-6 with different runaway heads are displayed in Figure 7. The $C_{p}$ value of $f_{1}$ increased obviously when the runaway head transformed from $H=0.65 \mathrm{~m}$ to $H=1.28 \mathrm{~m}$, but increased slightly when the runaway head was above $H=2.05 \mathrm{~m}$. The different $C_{p}$ value of $f_{1}$ accounts from the different location of MP1-6 (Figure 2). Since the MP2 and MP3 are symmetrically distributed at the two sides of the model pump, the $C_{p}$ value of $f_{1}$ between MP2 and MP3 were similar. The same reason leads to the similar $C_{p}$ value of $f_{1}$ between MP1 and MP4. However, the $C_{p}$ value of $f_{1}$ of MP2 was rather higher than that of MP1, which means the wake vortex core is away from the center of the rotation axis in elbow-type conduit. To be more specific, the rotation core of wake vortex in the elbow-type conduit was close to MP2 away from MP1. As for MP5, the $C_{p}$ value of $f_{1}$ with $H$ above $2.05 \mathrm{~m}$ was similar to that of MP2, meaning the influence degree of the wake vortex is similar. Besides, the $C_{p}$ value of $f_{1}$ of MP6 was lower than those of MP1-5 due to the remote location.

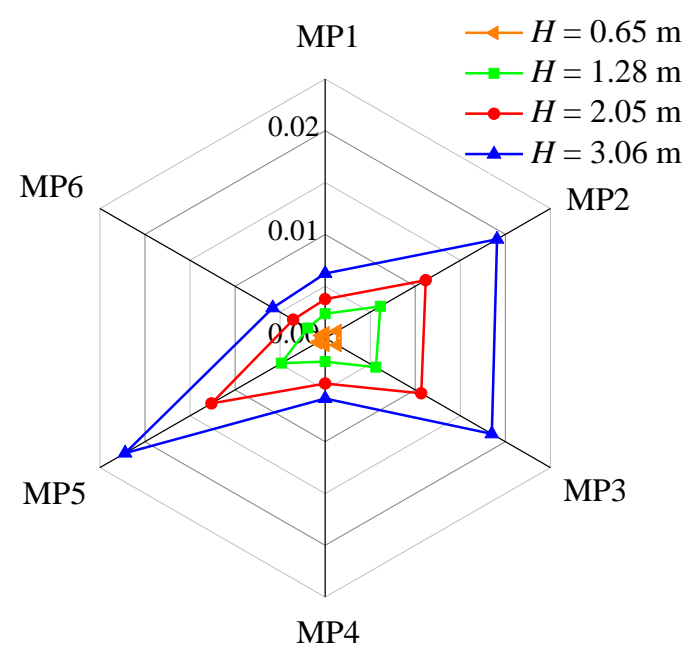

Figure 7. The $C_{p}$ value of $f_{1}$ among MP1-6 at $\alpha=+2^{\circ}$ with different runaway heads. 
In order to compare the $C_{p}$ value at the interface of the impeller and the inlet conduit (i.e., MP1 4) at different blade angles, the average pressure coefficient $C_{p}^{*}$ is introduced as follows:

$$
C_{p}^{*}=\frac{1}{m} \sum_{i=1}^{m} C_{p i}
$$

where $m$ is the number of MP to be around the impeller, here $m=4$, and $C_{p i}$ is the pressure coefficient of MPi.

The $C_{p}^{*}$ values under different runaway conditions are displayed in Figure 8 . It is observed from Figure 8a that the $C_{p}^{*}$ value of $f_{n}$ increased obviously with the runaway head. However, the $C_{p}^{*}$ of $f_{n}$ changed inconspicuously at different blade angles with the same runaway head, which may account from the randomness of the model test and the small difference of rotation speed at different blades. As for the $C_{p}^{*}$ value of $f_{\mathrm{BPF}}$ in Figure $8 \mathrm{~b}$, the $C_{p}^{*}$ value of $f_{\mathrm{BPF}}$ decreased slightly with the runaway head, which means the RSI was weakened under runaway condition. In addition, the $C_{p}^{*}$ value of $f_{\text {BPF }}$ decreased slightly with the blade angle, owing to the higher rotation speed at smaller blade angles. In Figure $8 \mathrm{c}$, it is shown that the change ruler of the $C_{p}^{*}$ value of $f_{1}$ was the same as that of $f_{n}$, which indicates the wake vortex is related to the rotation impeller. Moreover, the $C_{p}^{*}$ value of $f_{1}$ was higher than that of $f_{n}$ with the same runaway head, which shows that the pressure pulsation degree caused by the wake vortex is higher.

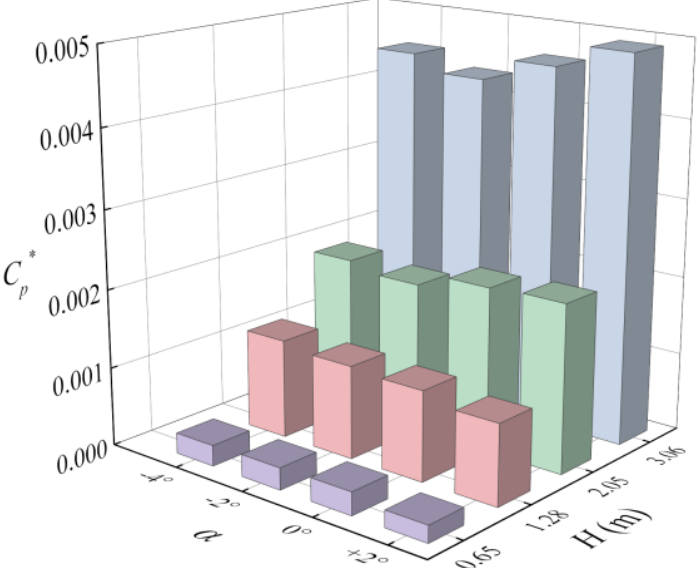

(a) $f_{n}$

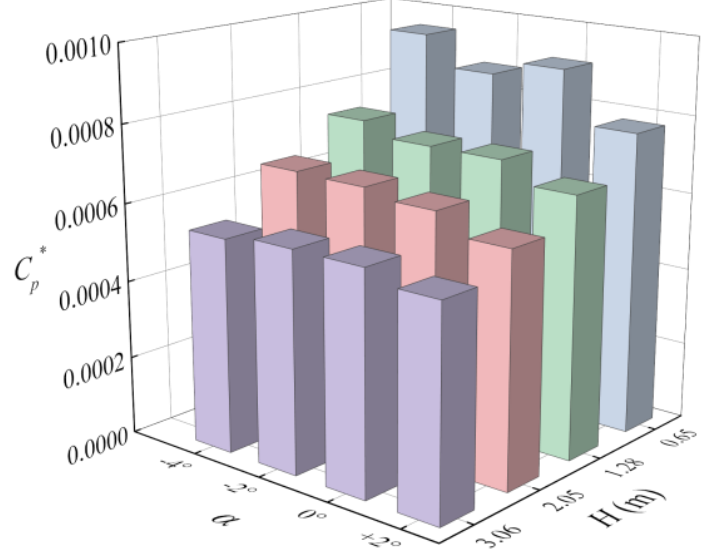

(b) $f_{\mathrm{BPF}}$

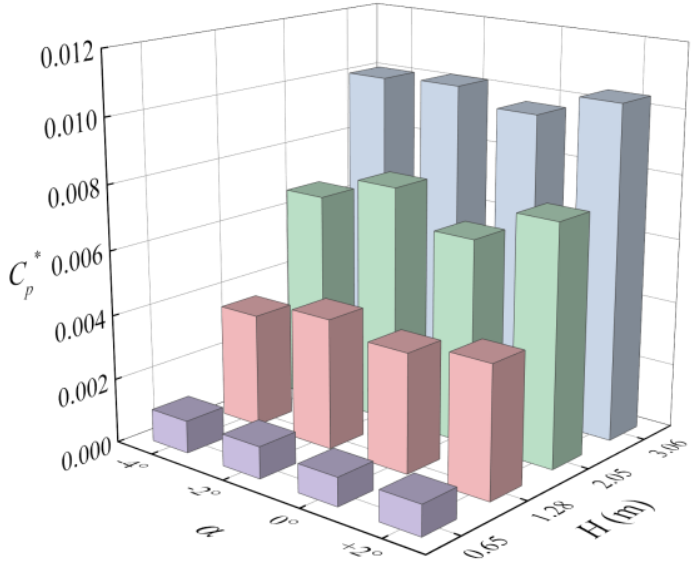

(c) $f_{1}$

Figure 8. The $C_{p}^{*}$ value with different blade angles and different runaway heads. 


\section{Conclusions and Expectation}

In this paper, the characteristics of pressure pulsation with different blade angles and different runaway head were tested and researched. To deeply analyze the pressure pulsation coefficient $C_{p}$ at different locations, MP1-4 were uniformly arranged at the impeller inlet section and, additionally, MP5 and MP6 were placed above and below the inlet conduit respectively. The time domain and frequency domain analysis were the main methods to obtain the change regulations. The main conclusions are summarized as follows:

(1) The $C_{p}$ value of the rotation frequency $f_{n}$ among MP1-4 increased obviously with the runaway head, but changed slightly at different blade angles with the same runaway head. Besides, the $C_{p}$ values of $f_{n}$ of MP5 and MP6 were lower than those among MP1-4, which means the influence range of the pressure pulsation caused by the rotation impeller is limited.

(2) Since the rotor-stator interaction is weakened during the runaway process, the $C_{p}$ value of the blade passing frequency $f_{\mathrm{BPF}}$ changed little with the runaway head, and the high-frequency harmonics of $f_{\mathrm{BPF}}$ are close to zero.

(3) Under the runaway condition, the wake vortex was easily induced in the inlet conduit. Moreover, the wake vortex frequency $f_{1}$ is related to $f_{n}$ (i.e., $f_{n} / f_{1}$ is about 2.9 at $\alpha=+2^{\circ}$ ). However, the $C_{p}^{*}$ value of $f_{1}$ was higher than that of $f_{n}$ with the same runaway head, which shows that the pressure pulsation degree caused by the wake vortex is higher.

(4) The $C_{p}$ value of $f_{1}$ among MP1-4 differed a lot, which means the wake vortex core is not in the center of the rotation axis.

(5) More deep research about the pressure pulsation under runaway conditions with different pump models can be carried out as the next step, and the characteristics of different multiples of rotation frequency should be different.

Author Contributions: Project administration, X.L., C.H., X.X., G.B., Z.Z., F.X. and Q.D.; Software, J.D.; Supervision, C.H.; Validation, J.D.; Visualization, J.D.; Writing—original draft, J.D.; Writing—review \& editing, J.D. and Q.D. All authors have read and agreed to the published version of the manuscript.

Funding: This research received no external funding.

Institutional Review Board Statement: Not applicable.

Informed Consent Statement: Not applicable.

Data Availability Statement: Not applicable.

Conflicts of Interest: The authors declare no conflict of interest.

\section{References}

1. Feng, J.; Ge, Z.; Zhang, Y.; Zhu, G.; Wu, G.; Lu, J.; Luo, X. Numerical investigation on characteristics of transient process in centrifugal pumps during power failure. Renew. Energy 2021, 170, 267-276. [CrossRef]

2. Lu, J.; Qian, Z.; Lee, Y.-H. Numerical investigation of unsteady characteristics of a pump turbine under runaway condition. Renew. Energy 2021, 169, 905-924. [CrossRef]

3. Su, W.-T.; Li, X.-B.; Xia, Y.-X.; Liu, Q.-Z.; Binama, M.; Zhang, Y.-N. Pressure fluctuation characteristics of a model pump-turbine during runaway transient. Renew. Energy 2020, 163, 517-529. [CrossRef]

4. Yang, Z.; Cheng, Y.; Xia, L.; Meng, W.; Liu, K.; Zhang, X. Evolutions of flow patterns and pressure fluctuations in a prototype pump-turbine during the runaway transient process after pump-trip. Renew. Energy 2020, 152, 1149-1159. [CrossRef]

5. Zhang, X.; Zeng, W.; Cheng, Y.; Yang, Z.; Chen, Q.; Yang, J. Mechanism of Fast Transition of Pressure Pulsations in the Vaneless Space of a Model Pump-Turbine During Runaway. J. Fluids Eng. 2019, 141, 121104. [CrossRef]

6. Fortin, M.; Houde, S.; Deschênes, C. A Hydrodynamic Study of a Propeller Turbine During a Transient Runaway Event Initiated at the Best Efficiency Point. J. Fluids Eng. 2018, 140, 121103. [CrossRef]

7. Fortin, M.; Houde, S.; Deschenes, C. Validation of simulation strategies for the flow in a model propeller turbine during a runaway event. In IOP Conference Series: Earth and Environmental Science; Desy, N., Deschenes, C., Guibault, F., Page, M., Turgeon, M., Giroux, A.M., Eds.; IOP Publishing: Bristol, UK, 2014; p. 032026.

8. Trivedi, C.; Cervantes, M.J.; Gandhi, B.K.; Dahlhaug, O.G. Transient Pressure Measurements on a High Head Model Francis Turbine During Emergency Shutdown, Total Load Rejection, and Runaway. J. Fluids Eng. 2014, 136, 121107. [CrossRef] 
9. Trivedi, C.; Dahlhaug, O.G. Interaction between trailing edge wake and vortex rings in a Francis turbine at runaway condition: Compressible large eddy simulation. Phys Fluids 2018, 30, 075101. [CrossRef]

10. Zhang, W.; Chen, Z.; Zhu, B.; Zhang, F. Pressure fluctuation and flow instability in S-shaped region of a reversible pump-turbine. Renew. Energy 2020, 154, 826-840. [CrossRef]

11. Trivedi, C.; Cervantes, M.J.; Gandhi, B.K. Investigation of a High Head Francis Turbine at Runaway Operating Conditions. Energies 2016, 9, 149. [CrossRef]

12. Hosseinimanesh, H.; Vu, T.C.; Devals, C.; Nennemann, B.; Guibault, F. A steady-state simulation methodology for predicting runaway speed in Francis turbines. In IOP Conference Series: Earth and Environmental Science; Desy, N., Deschenes, C., Guibault, F., Page, M., Turgeon, M., Giroux, A.M., Eds.; IOP Publishing: Bristol, UK, 2014; Volume 22, p. 032027.

13. Zhang, X.; Cheng, Y.; Yang, Z.; Chen, Q.; Liu, D. Influence of rotational inertia on the runner radial forces of a model pump-turbine running away through the S-shaped characteristic region. IET Renew. Power Gener. 2020, 14, 1883-1893. [CrossRef]

14. Yang, Z.; Liu, Z.; Cheng, Y.; Zhang, X.; Liu, K.; Xia, L. Differences of Flow Patterns and Pressure Pulsations in Four Prototype Pump-Turbines During Runaway Transient Processes. Energies 2020, 13, 5269. [CrossRef]

15. Zhang, X.; Cheng, Y.; Xia, L.; Yang, J.; Qian, Z. Looping Dynamic Characteristics of a Pump-Turbine in the S-shaped Region During Runaway. J. Fluids Eng. 2016, 138, 091102. [CrossRef]

16. Zhang, X.X.; Cheng, Y.G.; Xia, L.S.; Yang, J.D. Dynamic characteristics of a pump-turbine during hydraulic transients of a model pumped-storage system: 3D CFD simulation. In IOP Conference Series: Earth and Environmental Science; Desy, N., Deschenes, C., Guibault, F., Page, M., Turgeon, M., Giroux, A.M., Eds.; Iahr Symposium on Hydraulic Machinery \& Systems; IOP Publishing: Bristol, UK, 2014; p. 032030.

17. Li, J.; Liu, S.; Wu, Y.; Zhu, Y. 3D unsteady turbulent simulation of the runaway transient of the Francis turbine ASME. Fluids Eng. Div. Summer Meet. 2007, 42886, 2005-2011.

18. Liu, Y.; Zhou, J.; Zhou, D. Transient flow analysis in axial-flow pump system during stoppage. Adv. Mech. Eng. 2017, 9. [CrossRef]

19. Xia, L.; Cheng, Y.; Yang, Z.; You, J.; Yang, J.; Qian, Z. Evolutions of Pressure Fluctuations and Runner Loads During Runaway Processes of a Pump-Turbine. J. Fluids Eng. 2017, 139, 091101. [CrossRef]

20. Rohani, M.; Afshar, M. Simulation of transient flow caused by pump failure: Point-Implicit Method of Characteristics. Ann. Nucl Energy 2010, 37, 1742-1750. [CrossRef]

21. Afshar, M.; Rohani, M.; Taheri, R. Simulation of transient flow in pipeline systems due to load rejection and load acceptance by hydroelectric power plants. Int. J. Mech. Sci. 2010, 52, 103-115. [CrossRef]

22. Zhou, Q.; Xia, L.; Zhang, C. Internal Mechanism and Improvement Criteria for the Runaway Oscillation Stability of a PumpTurbine. Appl. Sci. 2018, 8, 2193. [CrossRef]

23. Ma, Z.; Zhu, B.; Tan, L. A study on the evolution of the instability in two model pump-turbine runners with large blade leans. In IOP Conference Series: Earth and Environmental Science; IOP Publishing: Bristol, UK, 2019; Volume 240, p. 072032. [CrossRef]

24. Feng, J.; Li, W.; Luo, X.; Zhu, G. Numerical analysis of transient characteristics of a bulb hydraulic turbine during runaway transient process. Proc. Inst. Mech. Eng. Part E J. Process. Mech. Eng. 2018, 233, 813-823. [CrossRef]

25. Xia, L.; Cheng, Y.; You, J.; Zhang, X.; Yang, J.; Qian, Z. Mechanism of the S-Shaped Characteristics and the Runaway Instability of Pump-Turbines. J. Fluids Eng. 2016, 139, 031101. [CrossRef]

26. Xia, L.S.; Cheng, Y.G.; You, J.F.; Jiang, Y.Q. CFD Analysis of the Runaway Stability of a Model Pump-Turbine. In IOP Conference Series: Earth and Environmental Science; IOP Publishing: Bristol, UK, 2016; Volume 49, p. 42004. [CrossRef]

27. Fu, X.; Li, D.; Wang, H.; Zhang, G.; Li, Z.; Wei, X.; Qin, D. Energy Analysis in a Pump-Turbine During the Load Rejection Process. J. Fluids Eng. 2018, 140, 101107. [CrossRef]

28. Tanasa, C.; Susan-Resiga, R.; Muntean, S.; Bosioc, A.I. Flow-Feedback Method for Mitigating the Vortex Rope in Decelerated Swirling Flows. J. Fluids Eng. 2013, 135, 061304. [CrossRef]

29. Bosioc, A.I.; Susan-Resiga, R.; Muntean, S.; Tanasa, C. Unsteady Pressure Analysis of a Swirling Flow With Vortex Rope and Axial Water Injection in a Discharge Cone. J. Fluids Eng. 2012, 134, 081104. [CrossRef]

30. Tănasă, C.; Bosioc, A.; Muntean, S.; Susan-Resiga, R. A Novel Passive Method to Control the Swirling Flow with Vortex Rope from the Conical Diffuser of Hydraulic Turbines with Fixed Blades. Appl. Sci. 2019, 9, 4910. [CrossRef]

31. Zhang, N.; Gao, B.; Xia, B.; Jiang, Q.-F. Effect of the volute tongue cut on pressure pulsations of a low specific speed centrifugal pump. J. Hydrodyn. 2020, 32, 758-770. [CrossRef]

32. Gu, Y.; Pei, J.; Yuan, S.; Zhang, J. A Pressure Model for Open Rotor-Stator Cavities: An Application to an Adjustable-Speed Centrifugal Pump With Experimental Validation. J. Fluids Eng. 2020, 142, 101301. [CrossRef]

33. Falvey, H.T.; Cassidy, J.J. Frequency and amplitude of pressure generated by swirling flow. In Proceedings of the IAHR 5th Symposium, Stockholm, Sweden, 21-26 March 1970; pp. 92-101. 